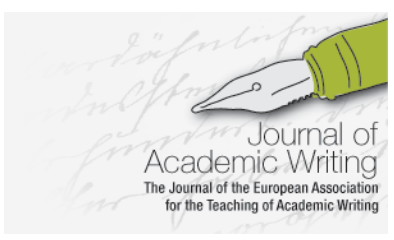

Journal of Academic Writing

Vol. 8 No 1 Summer 2018, pages 28-53 http://dx.10.18552/joaw.v81i1.429

\title{
Affective Language in Student Peer Reviews: Exploring Data from Three Institutional Contexts
}

\author{
Anna Wärnsby \\ Malmö University, Sweden \\ Asko Kauppinen \\ Malmö University, Sweden \\ Laura Aull \\ Wake Forest University, US \\ Djuddah Leijen \\ University of Tartu, Estonia \\ Joe Moxley \\ University of South Florida, US
}

\begin{abstract}
Although peer review is a common practice in writing classrooms, there are still few studies that analyze written patterns in students' peer reviews across multiple institutional contexts. Based on a sample of approximately 50,000 peer reviews written by students at the University of South Florida (USF), Malmö University (MAU), and the University of Tartu (UT), this study examines how students formulate criticism and praise, negotiate power relations, and express authority and expertise in reviewing their peers' writing. The study specifically focuses on features of affective language, including adjectives, expressions of suggestion, boosters and hedges, cognitive verbs, personal pronouns, and adversative transitions. The results show that across all three contexts, the peer reviews contain a blend of foci, including descriptions and evaluations of peer texts, directives or suggestions for revisions, responses to the writer or the text, and indications of reader interpretations. Across all three contexts, peer reviews also contain more positively glossed responses than negatively glossed responses. By contrast, certain features of affective language pattern idiosyncratically in different contexts; these distinctions can be explained variously according to writer experience, nativeness, and institutional context. The findings carry implications for continued research and for instructional guidance for student peer review.
\end{abstract}

\section{Introduction}

Timely, elaborate and detailed formative feedback has been shown to be unequivocally beneficial for learning (Black and Wiliam 1998). However, with more and more constraints on educational systems, instructors are often unable to provide the amount of feedback considered necessary. Peer review has been generally seen as a viable complement, or in some cases even an alternative, to instructor feedback (e.g. Bruffee 1984).

When peer reviewing, students are assumed to apply newly-acquired disciplinary knowledge and linguistic repertoires and registers, to develop these through the practice of using them on new models, and to learn to apply these skills in other social settings. In his research synthesis on peer review in English as a Second Language (ESL) writing classes, Chen (2016) points out that peer review, among other things, promotes collaborative learning and learner autonomy. 
In Vygotskyan terms, peers scaffold each other's learning effectively because this learning occurs within their zones of proximal development (Vygotsky 1978). Some studies indicate that students' reviews become more correlated with instructors' reviews over time (Moxley and Eubanks 2016), and that multiple student reviews are superior to single instructor reviews (Cho and Schunn 2007). In an ESL context, Hyland and Hyland (2006) argue that peer reviewing facilitates language development because it necessitates students to negotiate meaning in relevant interactions. Lundström and Baker's (2009) study on peer reviewing suggests that it is especially beneficial for student learning (see also Lansiquot and Rosalia 2015). The current practice of employing peer reviewing in writing courses - for native, ESL, and English as a foreign language $(E F L)$ speakers - is grounded also in the rise of process-oriented approaches to writing, where feedback focuses on the multi-draft process rather than on the final product (see Galbraith and Rijlaarsdam 1999, Kroll 2001).

With recent technological developments, peer review in writing courses has firmly moved into computer-mediated environments (CME). Comparing face-to-face peer review to peer review in CMEs, several studies identify numerous advantages of using the latter:

1) the possibility for asynchronous peer reviews in CMEs allows students to engage in peer reviews at their own convenience (Ware 2004);

2) CMEs have been characterized as less threatening than face-to-face interactions, which is particularly beneficial to beginner writers (Warschauer 2002);

3) students spend more time and give more feedback in CME peer reviews than in faceto-face peer reviews (Sullivan and Pratt 1996, Liu and Sadler 2003);

4) CME peer comments are often linguistically more complex (Fitze 2006);

5) instructors can more easily monitor the peer reviewing process in CMEs (Cheng 2007, Choi 2014).

When the technology works (Chong, Goff and Dej 2012) - and particularly if the students are trained to peer review (MacArthur 2016; Landry, Jacobs and Newton 2015; Liou and Peng 2009) - CME peer review is a valuable pedagogical tool. Geithner and Pollastro (2016) have demonstrated that engaging in peer reviews not only increases writing skills but also improves scientific literacy. However, peer reviews are still underused and understudied in higher education (Dysthe and Lillejord 2012; Nicol, Thomson and Breslin 2014), despite the convincing bulk of research on the positive aspects of CME peer reviews as an educational tool. Yet, several of these studies are conducted in highly local contexts on limited data. For example, Warschauer's ethnographic study (2002) illuminates three teachers' beliefs on the consequences of using ICT in a writing classroom. Although Chong, Goff and Dei's experimental study (2012) was conducted on a respectable sample of about 500 students, all these students were from the same course and engaged in the same assignment; the authors themselves call their study 'an anecdotal comparison' of on-line and face-to-face peer reviews (2012: 72).

In this paper, we explore peer reviews conducted within a recently developed CME: MyReviewers (see http://myreviewers.com). ${ }^{1}$ An e-learning environment developed by USF in consultation with writing program instructors and administrators in the U.S. and Europe, MyReviewers is designed to help instructors to organize their writing courses and to help students to structure their learning and writing processes. Within MyReviewers, a suite of tools facilitates peer reviews, including document mark-up (highlights, sticky notes), customizable rubrics, and community comments which link to a library of articles, exercises, and videos (Figure 1). Instructors assign anonymous peer review partners or groups. After being assigned to a peer review group, students log in to the CME and respond to each other's work using the above-mentioned tools.

\footnotetext{
${ }^{1}$ Joseph M. Moxley is the inventor of MyReviewers, which is used in this research. Joseph M. Moxley and the University of South Florida have a financial interest in MyReviewers LLC. These interests have been reviewed and managed by the University in accordance with its Institutional and Individual Conflict of Interest policies.
} 


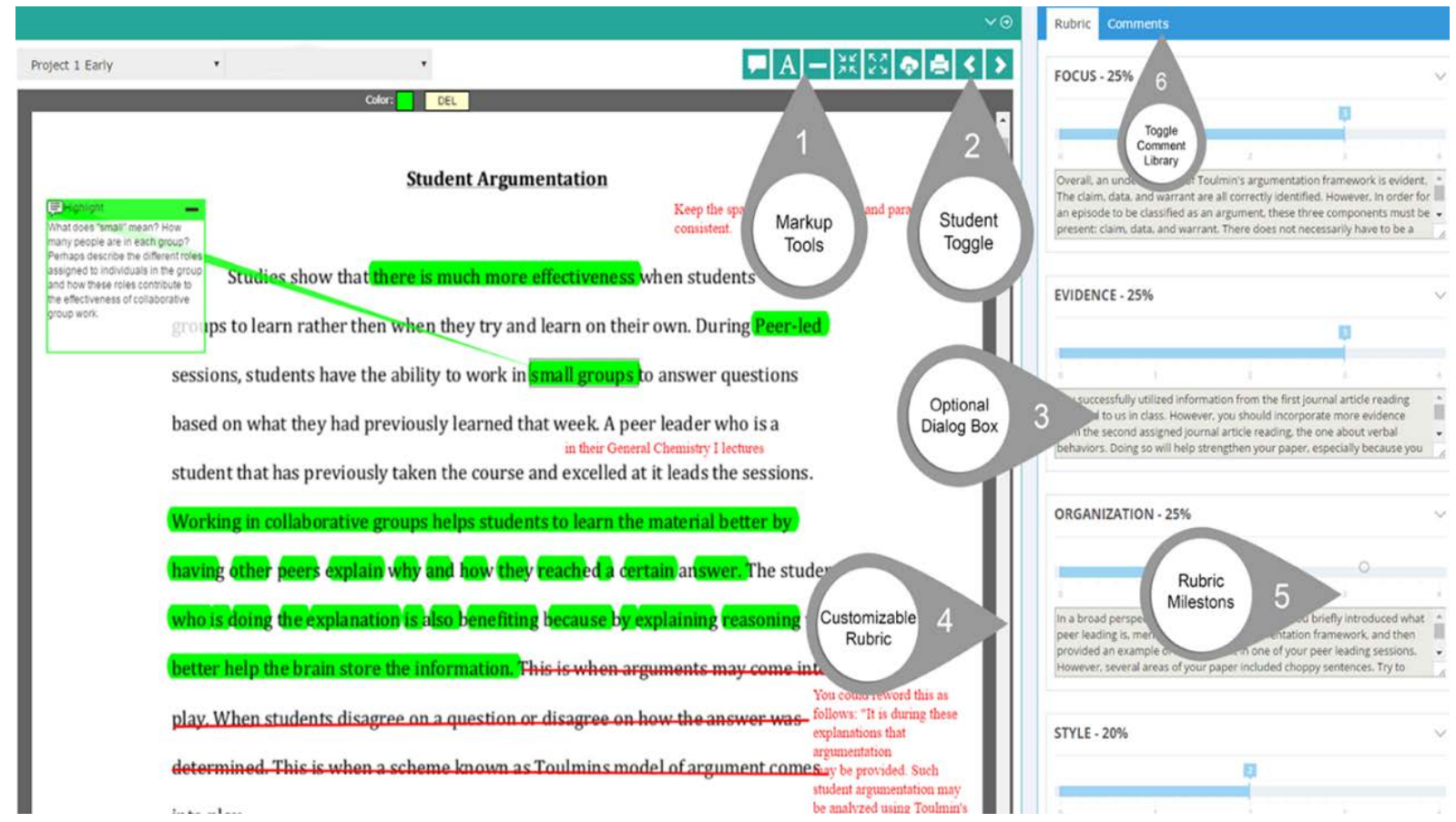

Figure 1. Markup in MyReviewers

After all peer reviews are completed, MyReviewers aggregates all the comments and scores that a student received from peers to help students access this data easily and to help instructors monitor students' progress. When peer reviewing, students can

1) use mark-up tools to comment directly on their peers' writing;

2) offer community comments;

3) offer both formative and summative comments using the grading criteria in the course rubric;

4) evaluate peer review received; and

5) make decisions for revision.

In this paper, we focus specifically on formative peer comments (see 3 in Figure 1).

Peer review has been investigated in several studies, many of which focus on the importance of understanding the role of formative feedback for revision. For example, Nelson and Schunn (2009) classify effective peer feedback into two distinct discourse categories: cognitive (summaries, comment scope and specificity, explanations) and affective (explicit criticism and praise). Measuring these categories on a large set of web-based peer review data, they concluded that feedback was most effective, i.e. effective in terms of prompting revision, when it included:

1) summarizing evaluative comments;

2) specific comments on the text as a whole; and

3) identifications of localized problems with explanations.

Further, Nelson and Shunn (2009) found that the affective category was not strongly linked to feedback prompting revision. This has also been confirmed by a similar study conducted by Leijen (2017) (see also Leijen and Leontjeva 2012). Leijen (2017), however, attributes the lack of evidence for affective features to the complex nature of measuring affective features in peer review. Another study focusing on what makes peer reviews successful, i.e. successful in terms of receiving high grades, is by $\mathrm{He}(1993)$. Anchoring her study in the functional approach to language (Halliday and Hasan 1976), He (1993) analyzed a small sample of peer reviews for what kind of discourse features were present in successful peer reviews as opposed to unsuccessful peer reviews as measured by three external expert evaluators. She found that in 
successful peer reviews the following features were always present: praise; descriptions of the review process and of the text; suggestions or criticism; and hedging. These features can also be seen as part of Nelson and Schunn's (2009) cognitive and affective discourse features. However, researchers do not agree on what constitutes indicators of effective and successful peer review practices or how these are to be identified in the data.

Looking at a sample of oral peer review, Lockhart and $\mathrm{Ng}$ (1995) identify four stances peer reviewers assume when giving feedback: authoritative; interpretative; probing; and collaborative. Depending on the stance - i.e. how students express their authority and expertise, how they negotiate power relations and how they interpret the peer review task - the function, content, and the presence of affective discourse features of feedback was shown to vary. Similar categorization, specifically of on-line peer review, has been proposed by Garrison, Anderson and Archer (1999), who outline five phases of negotiation and knowledge construction in CME: sharing and comparing; dissonance; negotiation; co-construction; testing; and application

Using Garrison, Anderson and Archer's (1999) community of inquiry model - which assumes that learning for the individual occurs through the interaction of cognitive presence, social presence, and teaching presence - Yallop (2016) suggests that specifically the element of social presence highlights how learners negotiate meaning on-line through their language. Criticizing on-line peer interactions, Liang (2008) claims that although peer discourse contained meaning negotiations, content discussions, error corrections, task management, and technical comments, most of this discourse was constituted by social talk. Accordingly, a further study is needed to ascertain whether this may be true of all peer review or is characteristic of only Liang's particular context. In general, understanding the context - be it institutional, ethnic, linguistic, disciplinary or other - in which peer reviews are implemented may help design the task in a most effective way (Choi 2014, Leijen 2017).

Many of the aforementioned studies were concerned with describing effective peer reviews, analyzing the discourse of peer review, and outlining the functions of typical peer review interactions. Few studies, however, pay attention to the role of linguistic choices to identify patterns in peer reviews; some of these studies are discussed in Material and Method. Even fewer studies make comparisons across large data samples from different contexts. In this study, we focus on the affective and cognitive discourse in peer reviews as a way to investigate how linguistic expressions help us identify patterns of criticism and praise across contexts. Although this study uses a general corpus methodology, it is not concerned with statistical analyses of the data or, at this stage, with robustly generalizable conclusions. The main audience for this study are general researchers and instructors in the field of teaching writing, not corpus linguists.

\section{Aim and Research Questions}

This study explores quantitatively some linguistic patterns of formulating criticism and praise, negotiating power relations, and expressing authority and expertise in peer reviews from USF, MAU and UT. The research questions are:

1) What similarities and differences can be found across the contexts?

2) How can these similarities and differences be explained?

3) What can these similarities and differences tell us about conventions of peer review in different contexts?

\section{Material and Method}

Access to large amounts of data is the most significant recent change in writing research. This makes possible - and necessitates - new questions and techniques of inquiry into writing patterns, testing of exploratory questions, and teasing out what kind of information such data can be made to yield. This explorative, descriptive study analyses authentic peer reviews from 
three educational contexts and tests how quantitative corpus methodology can inform our understanding of the ways in which students engage in this pedagogical practice. The study is informed, in particular, by Big Data research designs in the humanities (Manovich 2012, Moxley 2013, Dixon and Moxley 2013, Moxley and Eubanks 2016), corpus research (Biber, Conrad and Reppen 2011), and corpus research in intercultural rhetoric (Belcher and Nelson 2013).

\section{The settings}

The data emanates from three university contexts. The USF data comes from beginner undergraduate students taking First-Year Composition (FYC) courses with many different instructors, in which the students are mostly native speakers of English (L1). The MAU data also comes from beginner undergraduate students from different disciplinary programs, though all are in the same course with the same instructors and instructions. These MAU students are predominantly non-native speakers (mostly ESL with native-like command of English, but also EFL who are proficient speakers of English, see Sundqvist and Sylvén 2014 and Ushioda 2013). The UT data comes from graduate students from different disciplinary programs, studying different courses; these students are non-native speakers (EFL). The collection and use of the data for the study has been approved by The USF Institutional Review Board (IRB), The Regional Ethical Vetting Board in Lund, and The Research Ethics Committee of the University of Tartu.

Two obvious variables in this study are levels of education (beginner vs. experienced students) and English nativeness (L1 vs. ESL/EFL). ${ }^{2}$ Each institution's academic writing context adds an additional variable, which is illuminated by instructional materials including course and assignment descriptions. We discuss similarities and differences in the peer review findings across these different variables in Results and Analysis.

\section{The data}

This study analyses peer reviews conducted in MyReviewers between 2014 and 2016. The data from the three universities vary in size: the USF data contains 44,105 individual peer reviews, MAU 2,276 individual peer reviews, and UT 647 individual peer reviews.

The differences in numbers of peer reviews are reflected also in the size of the text samples. The USF corpus has the largest number of words, 6,824,405; the MAU corpus has 381,184 words; the UT corpus is the smallest sample with 67,046 words. We included all peer review submissions, regardless of the grade or the degree of completeness: any submission saved in MyReviewers was included in the corpus. The USF and MAU submissions were all in English, but the UT submissions include some elements in Estonian as well. However, this does not significantly affect the UT results.

The experienced UT students are concise when peer reviewing, with 104 words on average per peer review. The USF and MAU beginner students are more loquacious, with 155 and 154 words per peer review, respectively. As mentioned, the USF students are native speakers, the MAU students are mostly ESL learners, and the UT students are mostly EFL learners. As ESL learners are usually more proficient than EFL learners, this would go some way toward explaining the MAU students' near-native quantity of peer comments. This difference in the extent of comments between MAU and UT students may also stem from the difference in levels of education between the students. Patchan, Schunn and Correnti (2016), for example, have found that more comments may not stimulate revision and may not help peers to improve the overall quality of writing, and it is possible that the UT students, who are mostly MA and PhD students, have learned to be more concise in their comments in the course of their studies.

The heterogeneity of the contexts and data sizes makes statistical analysis unwieldy and, for the purposes of this study, impractical. Hence, this study does not attempt to make statistically valid generalizations about the distribution of affective discourse features in different contexts. Rather, it aims to explore the possibility of answering qualitative questions with disparate "realworld" data, which can nevertheless be a source of rich information and provide unexpected

${ }^{2}$ In this study, we have not considered other variables such as age, background, gender, or ethnicity, although MyReviewers can yield this type of data as well. 
insights. In our analysis and discussion of the results, we are concerned with exploring the relative differences between data samples and, therefore, only calculate the results in percentages.

\section{Search method}

We used Anthony's (2017) freeware concordance program AntConc for Macintosh OSX (10.710.10) to query the data with specific search lists (outlined in the next section) and noted how often the keywords (see Appendix) in the lists appeared in different contexts. We treat these keywords in the lists as indicators of affective discourse features in the corpus, coding criticism and praise patterns. We proceed by explaining each search list, and hypothesize what tendencies or features each indicates.

\section{Search lists}

To target the interpersonal dimension of peer review, we focus specifically on linguistic expressions coding criticism and praise. Nelson and Shunn (2009) argue that expressions which code criticism and praise in peer reviews are features of affective language (for example, hedges, personal attribution and questions). To identify these expressions, we draw from existing research on affective and cognitive discourse features (Mirador 2014).

We used several overlapping strategies to create the search lists. First, we identified what linguistic indicators appear in the contexts of criticism and praise, power relations, expressions of authority and expertise. We investigate boosters (really, indeed) and hedges (maybe, perhaps), cognitive verbs (think, believe), adjectives (good, clear), expressions of suggestion (suggest, you better), personal pronouns ( $I$, we, you), and adversative transitions (however, on the other hand).

Some search lists were taken directly from previous research (Aull 2015). Other search lists we put together by gleaning existing word lists and selecting the ones that addressed the issue we wanted to isolate. Some lists also include keywords from a qualitative pilot study on the MAU data (50 randomly chosen peer reviews). These latter keywords may arguably contain a MAU bias; but as the results show, the high prevalence of these keywords in the USF and UT data seems to counter such suspicion. Creating the search lists was challenging. We find ourselves agreeing with Garrison, Anderson and Archer's note that ' $[\mathrm{t}] \mathrm{h}$ e challenge is to choose indicators that are specific enough to be meaningful, but still broad enough to be usable in the actual analysis' (1999: 94). As Mirador (2014) argues, the possibility of using lexico-grammatical elements to identify particular discourse features may in the future open up the possibility of (automatically) tagging large corpora to glean particular features of peer review. The search lists we have compiled and tested in this study may be used for this purpose in the future. Below, we explain how each list was put together (see Appendix for complete lists).

\section{Adjectives}

To create a comprehensive list of adjectives, we first made a small-scale qualitative investigation of the MAU data; however, this did not result in a satisfactorily varied list of individual adjectives. We then searched for the adverbs very, rather and quite and the adjectives they collocated with in the entire data set and extracted all the adjectives this search revealed. This led to a restricted, but initial, working list. We take adjectives in the context of peer reviews to be expressions of criticism or praise that also code reviewers' attitudes to peers' writing - whether positive or negative, whether positioned in the middle of the meaning scale, or at its extremes (e.g. from very clear to clear to unclear), whether emotionally charged (Rocklage and Fazio 2015) - and thus index engagement and social presence (Rourke et al. 1999).

\section{Expressions of suggestion}

To come up with a list of expressions of suggestion, we first made a small-scale qualitative analysis of the MAU sample, and complemented it with a selection from VerbNet, which is 'the largest on-line verb lexicon currently available for English' (VerbNet n.d.), and FrameNet, which is 'a lexical database of English that is both human- and machine-readable, based on annotating examples of how words are used in actual texts' (FrameNet n.d.). We hypothesize 
that expressions of suggestion indicate an active engagement with the writer or the text and point to where criticism or praise may be located (Kipper et al. 2008).

\section{Boosters and hedges}

The list of boosters and hedges comes from Aull (2015), whose list has been compiled using both quantitative and qualitative analysis of FYC writing data. Since peer reviewing can be thought of as a potentially face-threatening situation (Brown and Levinson 1987) in that the students subject themselves to criticism by peers (Nguyen 2008), boosters and hedges including cognitive verbs - may indicate how reviewers negotiate illocutionary force in potentially face-threatening context. Boosters may increase the force of praise and criticism; hedges may decrease the force of praise and criticism. We have disregarded whether boosters and hedges appear in the context of criticism or praise since we cannot yet access context of use quantitatively.

\section{Cognitive verbs}

To create a list of cognitive verbs, we first made a small-scale qualitative analysis of the MAU data, the results of which we complemented with verbs from VerbNet and FrameNet (see above). We have a dual hypothesis for cognitive verbs. Firstly, these verbs have been shown to often collocate with $1^{\text {st }}$ person subjects to indicate a high degree of reflective stance and modal distance (Wärnsby 2006). That is, students using many cognitive verbs entertain multiple viewpoints: instead of selecting one viewpoint as the right solution, they present these viewpoints as suggestions. Secondly, cognitive verbs also relate to evidentiality: students using them motivate their criticism and praise by offering some evidence for their reviews (Mirador defines evidentiality in tutor feedback as 'an informative comment, which offers factual information to stress a point made by the tutor ... [and] points to tutors as a source of knowledge' (2014: 46)).

\section{Personal pronouns}

The most self-evident list is that of $1^{\text {st }}$ and $2^{\text {nd }}$ person personal pronouns. Consequently, we searched all forms of $1^{\text {st }}$ person singular $(I), 1^{\text {st }}$ person plural (we), and $2^{\text {nd }}$ person (you). Our hypothesis is that personal pronouns code interactivity/social presence in three different ways: engagement ( $1^{\text {st }}$ person singular); inclusion ( $1^{\text {st }}$ person plural); and engagement/disalignment ( $2^{\text {nd }}$ person). More precisely, we take the $1^{\text {st }}$ person singular to indicate that the peer review focus is on the peer reviewer's own performance: perceptions, hesitations, suggestions, and evaluations (see also He's (1993) description of review). Further, we take the $1^{\text {st }}$ person plural to indicate that the peer review focus is on articulating common ground: referencing shared course materials, learned practices, etc. (e.g., Garrison, Anderson and Archer's (1999) community of inquiry). The $2^{\text {nd }}$ person pronouns are taken to indicate that the peer review focus is on directing the writer's performance, and possibly also on moments of disagreement with the writer's position (compare with the four stances in Lockhart and $\mathrm{Ng}(1995)$ ).

\section{Adversative transitions}

The adversative transitions list was put together using a variety of strategies. We used adversative transitions mentioned in Quirk et al. (1985), Biber et al. (1999), and Huddlestone and Pullum (2002), but also adversative transitions mentioned in various writing guides, such as adversative transitions lists provided by Purdue's OWL and USF's The Writing Commons. The hypothesis is that adversative transitions indicate reviewers' disalignment with peers' texts, and mark a localizable change in sentiment orientation (Li, Huang and Zhu 2010), and thus constitute pragmatic indexes of power and authority (Aijmer 2013). The more adversative transitions there are in the peer review, the more disalignment there is with the writer's position.

\section{Results and Analysis}

In interpreting our results, we aimed to explore how linguistic indicators of praise and criticism identified in the pilot study and in previous research are distributed across the three contexts: USF, MAU, and UT. We group these indicators to express three 'moves' with which criticism and praise are communicated in peer reviews. Following Mirador, we understand the concept 
of move as 'the staging of an intent, and the corresponding and 'observable shift' in the intent as expressed in the text by the interlocutor of the message' (2014: 41). The first move, which we call 'expressing criticism and praise,' is facilitated by adjectives (This is a clear introduction) and explicit expressions of suggestion (I suggest you add a reference here). The second move we call 'negotiating criticism and praise,' and it is facilitated by boosters (This certainly reads well), hedges (Maybe you can change the title) and cognitive verbs (I think this is ok) that modulate strategies with which criticism and praise are delivered. The third move we call 'focusing criticism and praise,' and it is facilitated by personal pronouns (You could make this shorter, I know the instructions were different) and adversative transitions (However, in the introduction...), which signal writer/reviewer focus and disalignment with the writer's position respectively. The percentages in Figures 2-9 in this section identify the proportion of words in collated peer reviews allocated to each search list, compared to the total word count.

\section{Expressing criticism and praise}

The move of expressing criticism and praise is indicated (among other linguistic expressions that are not within the scope of this study) by adjectives and expressions of suggestion.

\section{Adjectives}

The data in Figure 2 suggests that the more experienced students in UT do not express criticism and praise through adjectives to the same degree as the beginner students in MAU and USF do.

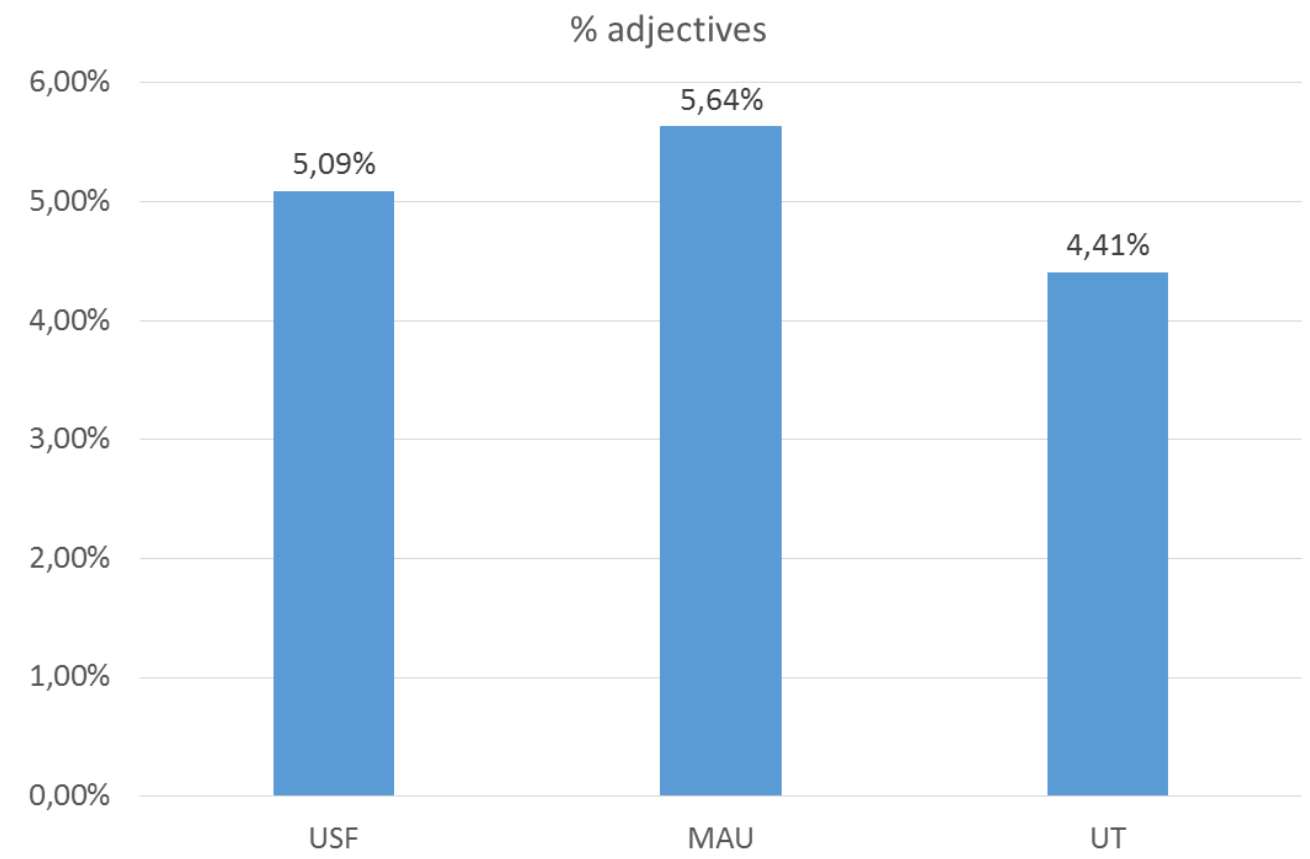

Figure 2. Distribution of adjectives

The use of adjectives across the data sets is comparable to the approximate $5 \%$ frequency of adjectives in the Longman Spoken and Written English Corpus (Biber 2006); the MAU students use slightly more, the USF students use slightly less, and the UT students use the fewest adjectives when peer reviewing. That an inherently evaluative process of peer reviewing does not stimulate more extensive adjective use is perhaps surprising. Given that non-native speaker academics underuse adjectives compared to native speaker academics (Ağçam and Özkan 2015), our data warrants further investigation, since ESL students from MAU use more adjectives than the native speakers from USF, while the EFL students from UT use fewer adjectives than the native speakers from USF.

Lists of the ten most frequently used adjectives (Table 1) reveal a few distinctions in what the three groups focus on most in their peer commentary. 
Table 1. Most frequently used adjectives

\begin{tabular}{lllllll} 
& USF & & MAU & \multicolumn{2}{c}{ UT } & \\
1 & good & 74681 & good & 5363 & good & 501 \\
2 & great & 26488 & clear & 1616 & clear & 329 \\
3 & clear & 14928 & common & 1198 & important & 88 \\
4 & credible & 11297 & interesting & 1091 & last & 87 \\
5 & organized & 9919 & easy & 722 & interesting & 84 \\
6 & strong & 9460 & great & 515 & general & 82 \\
7 & easy & 8461 & present & 453 & different & 81 \\
8 & interesting & 8421 & last & 423 & understandable & 75 \\
9 & supporting & 6818 & hard & 383 & academic & 65 \\
10 & consistent & 6394 & short & 371 & long & 52
\end{tabular}

The USF list is the only one that includes credible and organized, both of which are consistent with the USF project descriptions and rubrics, which emphasize credible evidence and effective organization as key components. The UT list uses academic exclusively, perhaps as part of an emphasis on register/language use. The MAU and UT (but not USF) frequent adjectives include an emphasis on length (short, long). All three lists include the positive, though vague, adjective good and also emphasize clarity (clear) and accessibility (easy, hard, understandable; MAU also includes confusing outside of the top 10). Moreover, all three groups also seem to emphasize appraisal (interesting) and coherence of own review process or the text under review (last, consistent). Finally, all three groups also include mostly adjectives with a positive gloss, suggesting all three groups perceive positive evaluation to (often) be part of peer review. More work, however, could be done in the future on establishing the valency of the individual adjectives (i.e. how they place on a positive/negative scale) and their collocation patterns.

\section{Expressions of Suggestion}

Expressions of suggestion are equally frequent in the USF and MAU data, but they are less frequent in the UT data (Figure 3). The difference here may in part be explained by academic experience. That is, the graduate-level, more experienced, UT students may not feel the need to offer explicit suggestions to the same extent as the undergraduate beginner students at USF and MAU, and may code suggestions more implicitly or just point out drawbacks in writing rather than offer explicit suggestions (see the UT data on boosters and hedges in section 4.2.1). 


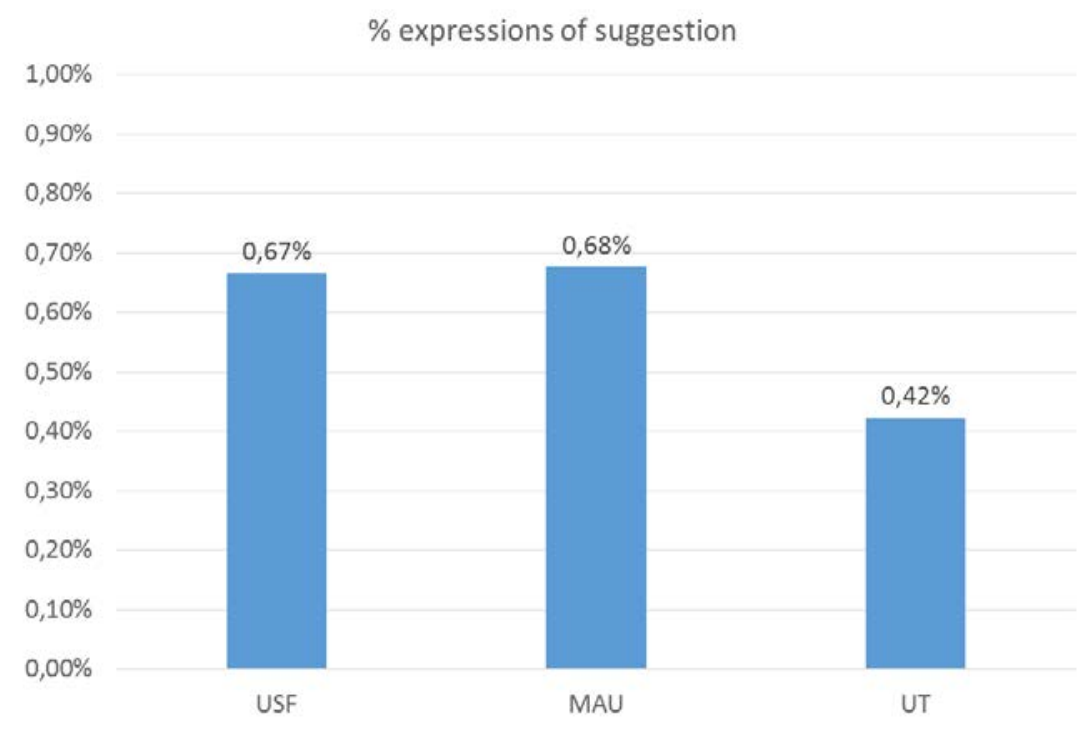

Figure 3. Distribution of expressions of suggestion

In light of the course materials from each institutional context, these findings suggest that students who are explicitly encouraged to offer explicit suggestions to their peers are more likely to do so. USF students are told to offer 'information that will help to improve' the writing, rather than only saying whether they liked it or not. Likewise, the MAU students receive explicit peer-review criteria that require identifying elements in peer texts as well as offering 'clear, motivated suggestions for improvement.' The UT course materials do not pointedly ask students to offer specific revision suggestions in peer review. Instead, they describe the qualities of professional feedback: 'The professional task of feedback givers is to communicate ideas and make suggestions. Feedback is not about hiding or diluting your observations, but about communicating them in a way that is constructive, forward-thinking and acceptable for the writer.'

Table 2. Most frequent expressions of suggestion

\section{USF}

1 try

2 better

3 you should

4 you could

5 I suggest

6 you may

7 you might

8 you may want to

9 you might want to

10 I would like to
MAU

13472

11786

8687 try

4933 better

1701 I suggest

1457

1039

726

607

347

you may you should

you could

I would like to

you might

you might want to

I recommend
UT

$\begin{array}{lll}613 & \text { better } & 89 \\ 534 & \text { you should } & 63 \\ 527 & \text { Try } & 46 \\ 471 & \text { you could } & 32 \\ 112 & \text { I would like to } & 25 \\ 109 & \text { I suggest } & 10 \\ 88 & \text { you might } & 8 \\ 45 & \text { I recommend } & 4 \\ 43 & \text { you may } & 2 \\ 20 & \text { you might want to } & 2\end{array}$

The expressions of suggestion (Table 2) in the MAU and UT reviews are slightly more directive, given the relative salience of you could and you should. In all three contexts, the students use evaluative better and directive try language regularly; also interesting is that in all three contexts, the students use a modal expression of necessity you should more often than the modal expression of possibility you could. As a hedge or possibility verb, the latter leaves more room for the writer to make a reasoned choice to follow their peer's directive or not, while the former suggests there is one "right" revision that the peer reviewer has determined and offered. 
Research on what kind of feedback leads to revision is not in agreement. He (1993) demonstrates that instructors value explicit suggestions for revision by awarding such peer reviews higher grades. According to Nelson and Shunn (2009), feedback is more likely to be implemented if explicit solutions to a problem are offered. However, Cho and MacArthur (2010) find non-directive feedback predicts more complex revisions than directive feedback. Further studies may reveal whether the UT students engage in more complex revisions than the USF and MAU students, and whether more explicit suggestions in peer reviews actually result in better writing and higher grades.

\section{Negotiating criticism and praise}

The move of negotiating criticism and praise is indicated by boosters, hedges, and cognitive verbs.

\section{Boosters and hedges}

Looking at the data (Figure 4), we can see that the UT students use boosters and hedges the most, while the USF and MAU students use fewer boosters and hedges. Also here, the difference is perhaps between the experienced and the beginner students. In addition, the USF students clearly use boosters more than the MAU and UT students, while the UT students use more hedges than the USF and MAU students.

The difference in the distribution of boosters cannot be explained with reference to academic experience (if this were the case, the USF and MAU students would behave in a more similar way). Rather, what we see here may be a contextual difference. That is, European students (MAU and UT) seem to be less enthusiastic or do not make as strong claims as the American students. The high percentage of boosters in the USF writing is indicative of the overwhelming use of amplified, individualistic, persuasive essays common to US writing education (Aull 2015; Aull, Bandarage and Miller 2017; Burstein, Elliot and Molloy 2016; DeStigter 2015; Heath 1993). However, the frequency of boosters in the USF data is surprising in light of research showing that, relative to native speakers, ESL/EFL writers use more boosters (Hinkel 2005; Hyland and Milton 1997). The distribution of hedges across the three contexts, on the other hand, is consistent with previous research that shows that experienced writers are more careful in expressing criticism and praise than inexperienced ones (Aull and Lancaster 2014).

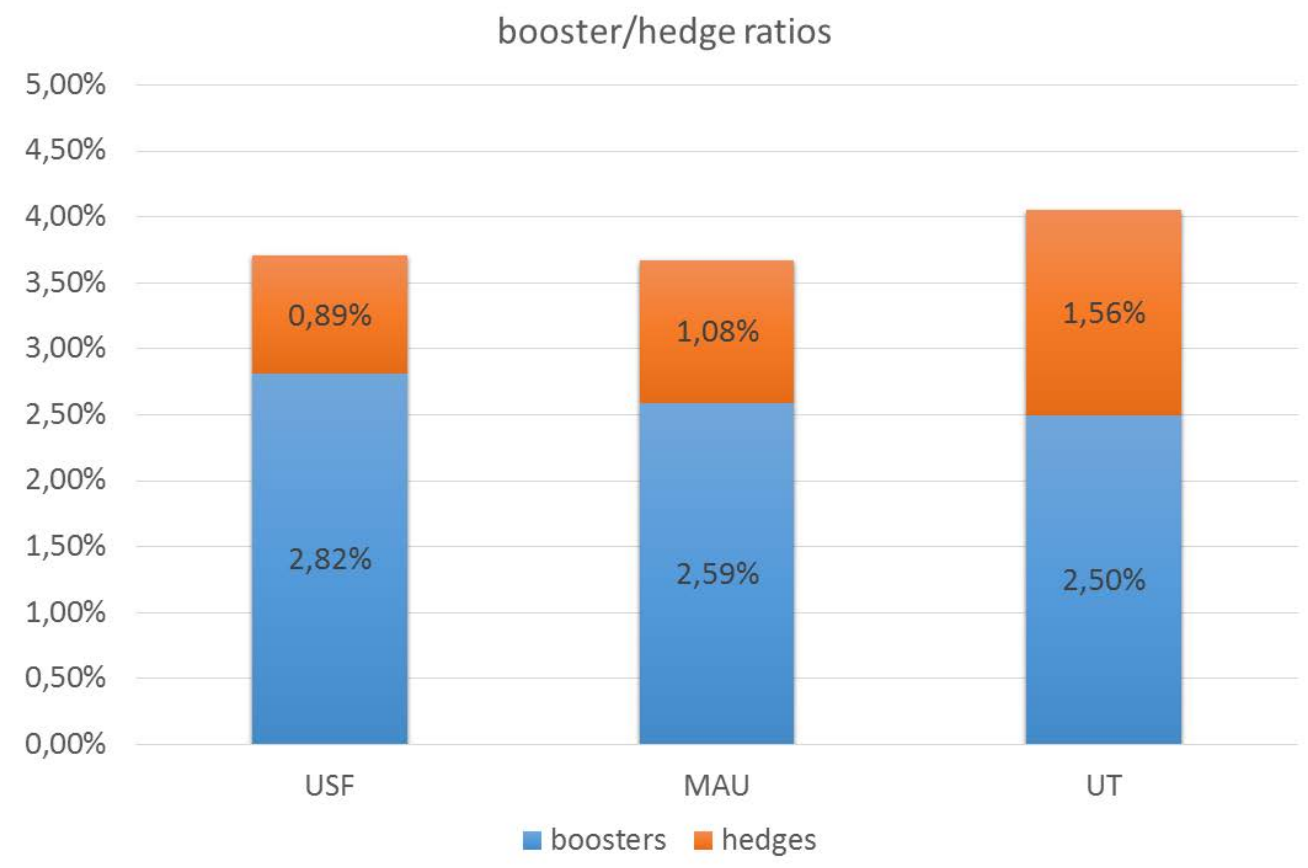

Figure 4. Ratios of boosters and hedges 
The boosters/hedges ratios show that all students use fewer hedges than boosters. This suggests that students in general do not qualify stances, suggestions, or directives, but that the experienced students are more diplomatic than the beginner students since they use more hedges. Furthermore, comparing adjectives to boosters and hedges, we may conclude that the USF and MAU students use more positively glossed adjectives and fewer hedges, while the UT students use fewer positively glossed adjectives and more hedges (Figures 3 and 4). Somewhat incongruently, the experienced students are less positive, though more diplomatic. Therefore, positivity and diplomacy in peer reviews should be seen as separate discourse features (see Davies (2006) on competent students being more critical, positive comments more holistic, and negative comments more specific; see also Nelson (2007) on specific, localized comments leading to revisions).

Table 3. Most frequent boosters

$\begin{array}{lllllll} & \text { USF } & & \text { MAU } & & \text { UT } & \\ \mathbf{1} & \text { very } & 49803 & \text { more } & 2667 & \text { more } & 428 \\ \mathbf{2} & \text { more } & 47486 & \text { very } & 1938 & \text { clear } & 329 \\ \mathbf{3} & \text { sure } & 19846 & \text { clear } & 1616 & \text { very } & 322 \\ \mathbf{4} & \text { really } & 16273 & \text { really } & 1025 & \text { clearly } & 115 \\ \mathbf{5} & \text { clear } & 14928 & \text { sure } & 466 & \text { quite } & 93 \\ \mathbf{6} & \text { clearly } & 4691 & \text { clearly } & 371 & \text { really } & 83 \\ \mathbf{7} & \text { definitely } & 2606 & \text { quite } & 231 & \text { sure } & 77 \\ \mathbf{8} & \text { quite } & 2030 & \text { always } & 76 & \text { definitely } & 35 \\ \mathbf{9} & \text { always } & 1695 & \text { definitely } & 53 & \text { known } & 14 \\ \mathbf{1 0} & \text { certain } & 1674 & \text { certain } & 50 & \text { surely } & 13\end{array}$

All boosters were retrieved disregarding whether they collocated with negation thus rendering a hedge (e.g. not really). Controlling for negation did not change the data pattern; boosters with negation in our data were surprisingly rare. Across the three contexts, few boosters are used very often, although the UT use of individual boosters is slightly more evenly distributed (Table 3). All three groups use a comparative word more frequently (though unlike MAU and UT, the USF students use intensifying very more often) and otherwise use mostly intensifying adverbs.

Table 4. Most frequent hedges

\begin{tabular}{llclcll} 
& USF & & MAU & \multicolumn{3}{c}{ UT } \\
$\mathbf{1}$ & seems & 6837 & maybe & 835 & maybe & 185 \\
$\mathbf{2}$ & seem & 6470 & might & 349 & seems & 144 \\
$\mathbf{3}$ & maybe & 5054 & seems & 319 & might & 63 \\
$\mathbf{4}$ & suggest & 4634 & seem & 270 & perhaps & 59 \\
$\mathbf{5}$ & may & 4266 & perhaps & 263 & seem & 49 \\
$\mathbf{6}$ & seemed & 4209 & suggest & 256 & suggest & 49 \\
$\mathbf{7}$ & might & 2757 & unclear & 159 & probably & 39 \\
$\mathbf{8}$ & somewhat & 1584 & may & 151 & possible & 34 \\
$\mathbf{9}$ & unclear & 1568 & probably & 118 & may & 24 \\
$\mathbf{1 0}$ & mostly & 1541 & mostly & 96 & unclear & 22
\end{tabular}

Although the students use more boosters, their use of hedges suggests a tendency to show diplomacy in peer review. All three lists (Table 4) include hedges that both qualify suggestions (maybe, somewhat, perhaps) and perception of the writers' work (seem/s). 


\section{Cognitive verbs}

Figure 5 shows that the MAU students, followed by the UT students, use cognitive verbs more often; the USF students use cognitive verbs less frequently.

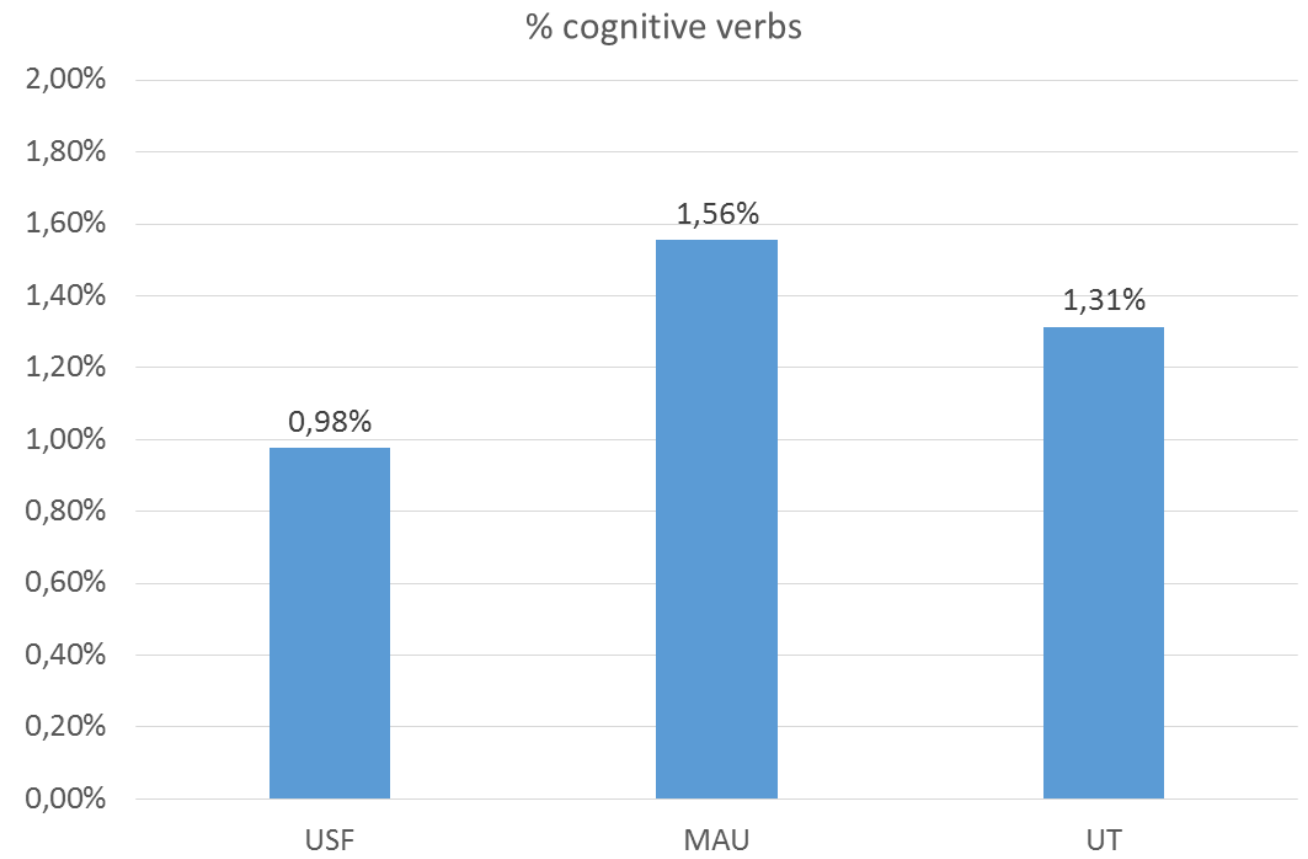

Figure 5. Distribution of cognitive verbs

It is possible that ESL/EFL writers use cognitive verbs similarly to hedges to promote diplomacy. Qualitative investigation of the context involving concordance searches should, of course, be carried out to establish if this is the case. However, combining hedges and cognitive verbs (Figure 6) seems to suggest that the difference in distribution of hedges and cognitive verbs may be explained with reference to the difference between native and ESL/EFL speakers.

cognitive verb/hedge ratios

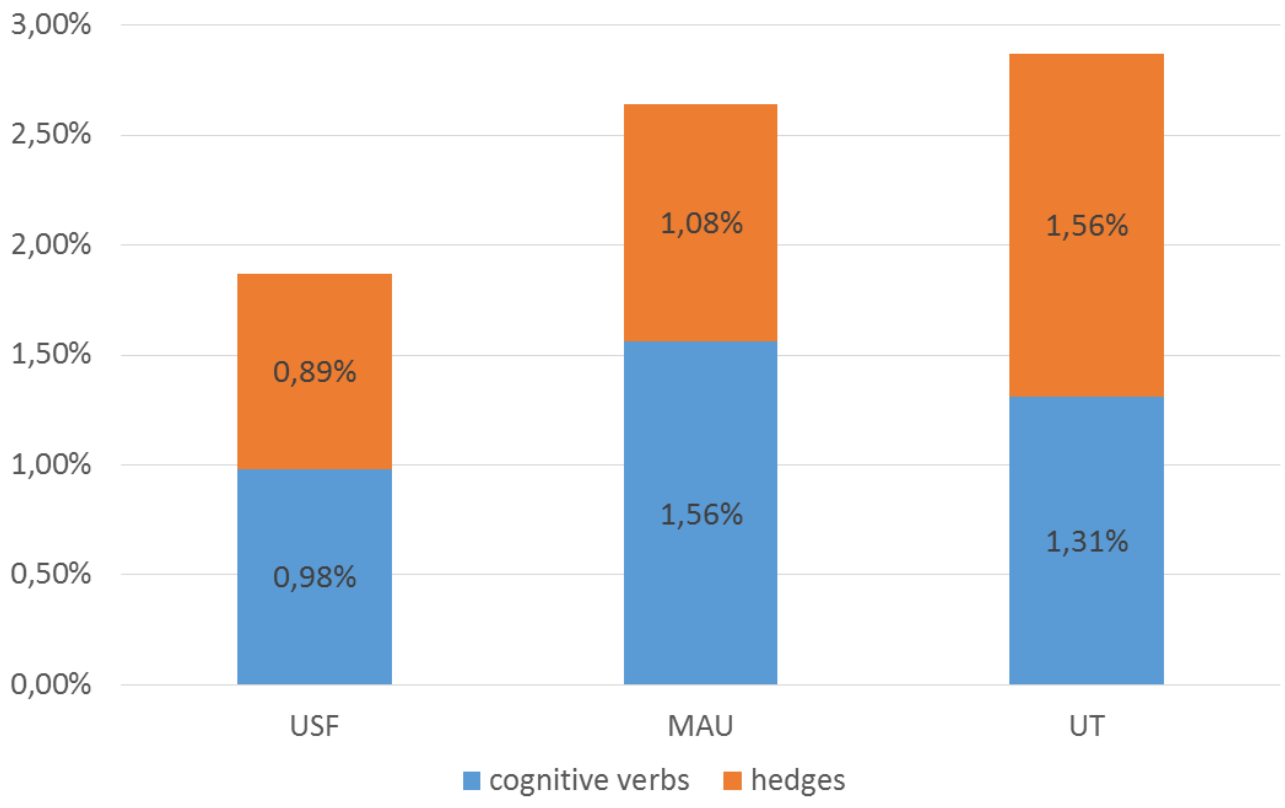

Figure 6. Ratios of cognitive verbs and hedges 
Similar to their frequent use of few boosters and hedges (Tables 3 and 4), the USF and MAU students use two verbs (think and like) very often, while other verbs not as frequently (Table 5). In the UT data, the verbs are more equally distributed. All three groups include a similar blend of verbs, including private and affective verbs (believe, feel), mostly cognitive process verbs (think, understand, know, question, consider, guess), and more rarely use of specifically hedging verbs (seem), writing process verbs (maintain), or evaluative verbs (like).

\section{Table 5. Most frequent cognitive verbs}

$\begin{array}{lllllll} & \text { USF } & & \text { MAU } & & \text { UT } & \\ \mathbf{1} & \text { think } & 18029 & \text { think } & 1957 & \text { think } & 271 \\ \mathbf{2} & \text { like } & 14861 & \text { like } & 1261 & \text { like } & 185 \\ \mathbf{3} & \text { seem } & 6470 & \text { know } & 580 & \text { understand } & 115 \\ \mathbf{4} & \text { understand } & 6132 & \text { understand } & 579 & \text { question } & 98 \\ \mathbf{5} & \text { feel } & 4842 & \text { feel } & 352 & \text { know } & 61 \\ \mathbf{6} & \text { know } & 4134 & \text { question } & 276 & \text { seem } & 49 \\ \mathbf{7} & \text { believe } & 3533 & \text { seem } & 270 & \text { guess } & 26 \\ \mathbf{8} & \text { question } & 3408 & \text { consider } & 264 & \text { consider } & 18 \\ \mathbf{9} & \text { consider } & 3334 & \text { believe } & 191 & \text { believe } & 14 \\ \mathbf{1 0} & \text { maintain } & 425 & \text { guess } & 75 & \text { feel } & 13\end{array}$

When it comes to negotiating criticism and praise, research is interestingly heterogeneous. Choi (2014) reports students offering more positively phrased comments than negatively phrased comments, whereas Davies (2006) reports the opposite tendency. Davies (2006) further observes positively phrased comments are more holistic, while negatively phrased comments are more specific, and that more competent students are more critical of their peers' writing. Hyland and Hyland (2001) notice instructors often mitigate negative specific feedback with positive holistic feedback, possibly as a face-saving exercise on behalf of the student (Yelland 2011). However, Nelson and Schunn (2009) demonstrate mitigating criticism has little effect on revision. Regardless of the combination of positive and negative feedback, Ferris (1997) and Mirador (2014) make a salient point that almost all peer reviews that lead to revision are negative: students tend to reflect and act on negative comments but disregard the positive peer comments (Hattie and Timperley 2007, Olsson Jers and Wärnsby 2017). Moreover, positive feedback may cause the student to misunderstand the significance of negative comments and ignore the necessity to implement changes (Shute 2008).

\section{Focusing criticism and praise}

The move of focusing criticism and praise is indicated by pronouns and adversative transitions in the peer reviews. We have divided our account of pronouns as focusing devices into writer focus (all forms of you), reviewer focus (all forms of $I$ ), and common ground (all forms of we) indicating different modes of reviewer's engagement, disalignment, and inclusion. The adversative transitions constitute an additional focusing device pointing to disalignment between the reviewer and the writer.

Writer focus (2nd person pronouns), reviewer focus (1st person singular pronouns) and common ground (1st person plural pronouns)

The USF students exhibit most writer focus, the MAU students somewhat less, and the UT students significantly less so (Figure 7). 


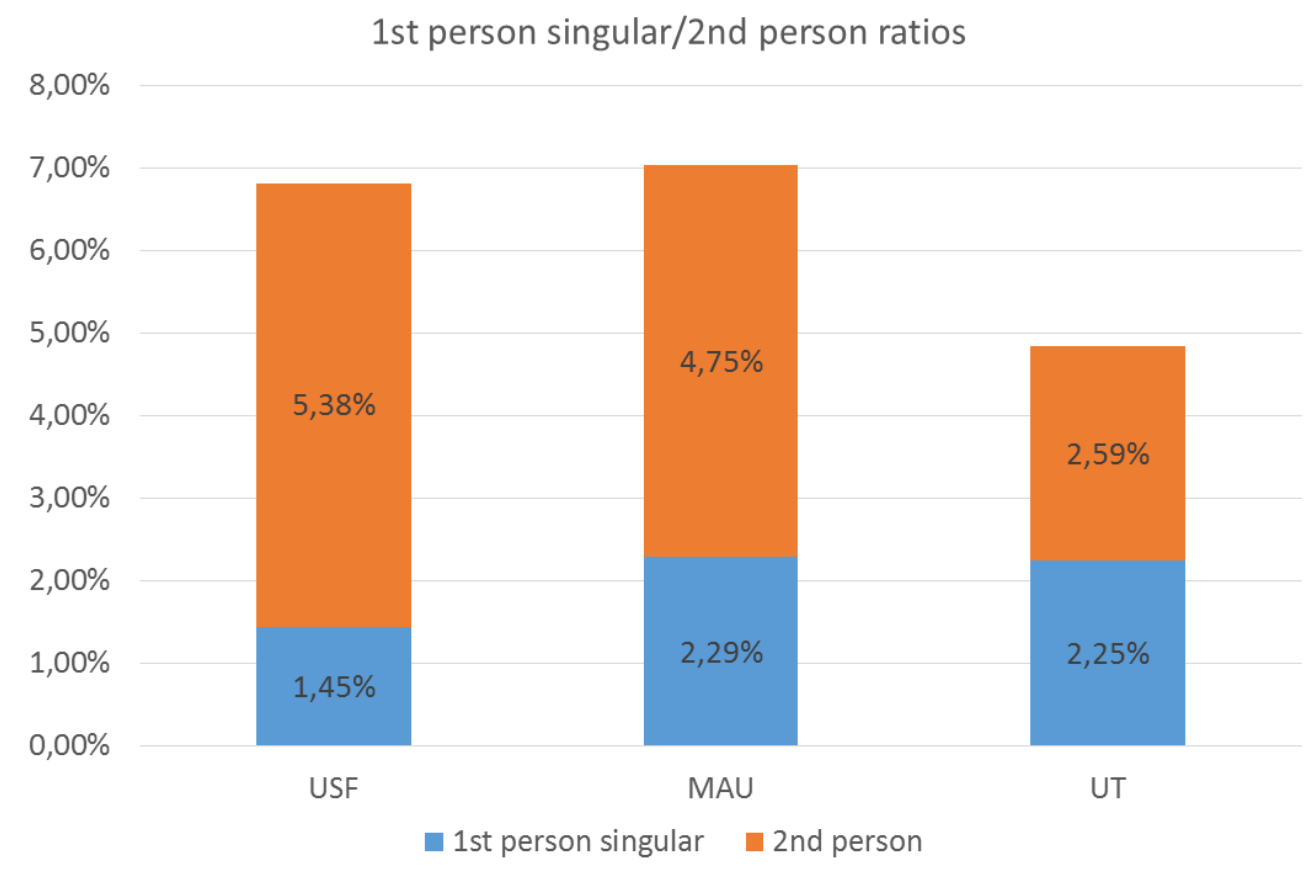

Figure 7. Ratios of $\mathbf{1}^{\text {st }}$ person singular and $2^{\text {nd }}$ person pronouns

The difference may stem from the peers' writing experience: the percentage of you is fairly similar in the beginner student data (USF and MAU). The UT data on you is consistent with their low use of expressions of suggestion (you appear in expressions of suggestions such as you should, you could (Table 2)). In a future qualitative study, it might be interesting to see when the writer is focused: whether you is used when suggestions, criticism, or praise are given.

The reviewer is focused in the MAU and UT data more than in the USF data. Consequently, while using you seems to be connected to student writing experience, the use of I cannot be explained by the same factor. The USF students clearly do not demonstrate the same degree of explicit reviewer engagement, or what Hyland (2005) refers to as self-mentions in stance features. This means that the students at MAU and UT use relatively high levels of epistemic features such as boosters (MAU) and hedges (UT) (Figure 4) as well as stance features of selfpositioning, and they position themselves more obviously as reviewers of the texts than do the USF students. The course materials may provide some explanation. As noted, the UT students are not explicitly instructed in course materials on how to peer review; perhaps this offers the UT students freedom to use a range of features in their peer reviews. The MAU students receive the most detailed information in a peer review rubric that requires peer reviews to include not only 'course metalanguage' but also interpersonal considerations: peer reviews 'should use a friendly and supportive tone.' This, perhaps, prompts the self-mentions. The USF students, on the other hand, are instructed to 'give the writer information that will help to improve what the writer has written' and may, therefore, place more emphasis on the text than the peer reviewer.

The number of occasions where students attempt to establish common ground by using an inclusive we is negligible across the three contexts (Figure 8): 4694 in USF data, 708 in MAU data, and 115 in UT data. 


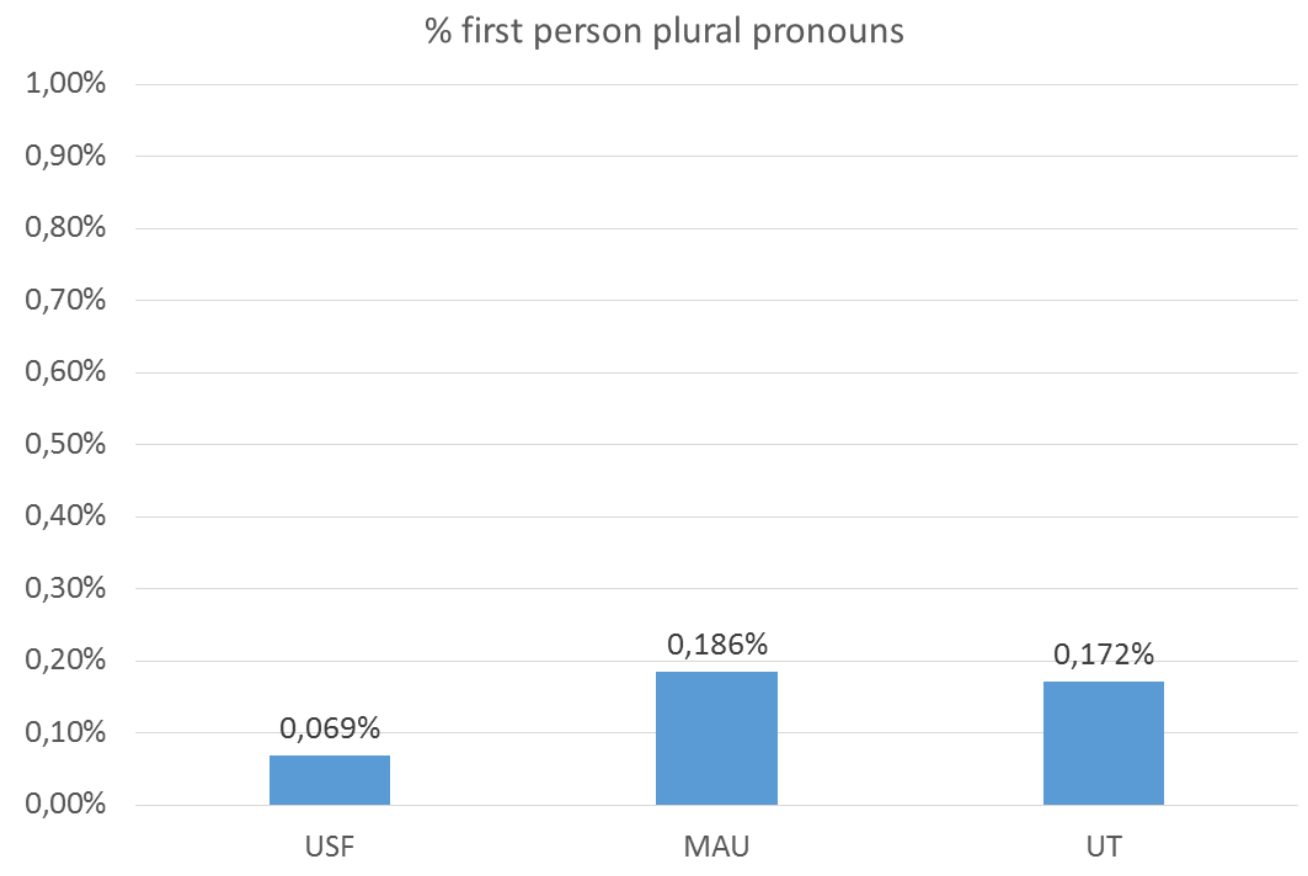

Figure 8. Distribution of $1^{\text {st }}$ person plural pronouns (we, us, our, ours)

Mitigating a potentially face-threatening situation of peer review (Brown and Levinson 1987, Yelland 2011) is clearly not tackled by creating common ground through the use of we. Future qualitative studies may reveal whether common ground is established by other means, for example, by references to shared assignment materials. In the present data set, we can see boosters, hedges, and cognitive verbs not only as linguistic expressions negotiating criticism and praise but also as creating common ground.

The ESL/EFL and native speaker distinction does not seem to be relevant in the distribution of pronouns in the three data sets. These patterns can be explained by the students' academic writing experience and their institutional contexts: the experienced students use fewer personal pronouns in general, and they distribute focus evenly between the writer and the reviewer. This suggests that the experienced students are more confident at inserting themselves into the interpersonal space of the peer review; it is a space of discussion where they take an active part and accept responsibility for their comments. For the less experienced students at USF and MAU - despite the different emphasis in the instructions on the writer and the reviewer, respectively - the focus clearly remains on the writer. The uneven distribution of focus between the writer and the reviewer in the USF and MAU data may also indicate that these students perceive academic writing as primarily argumentative or persuasive.

\section{Disalignment (adversative transitions)}

Adversative transitions are most frequent in the UT data, quite frequent in the MAU data, and infrequent in the USF data (Figure 9). 


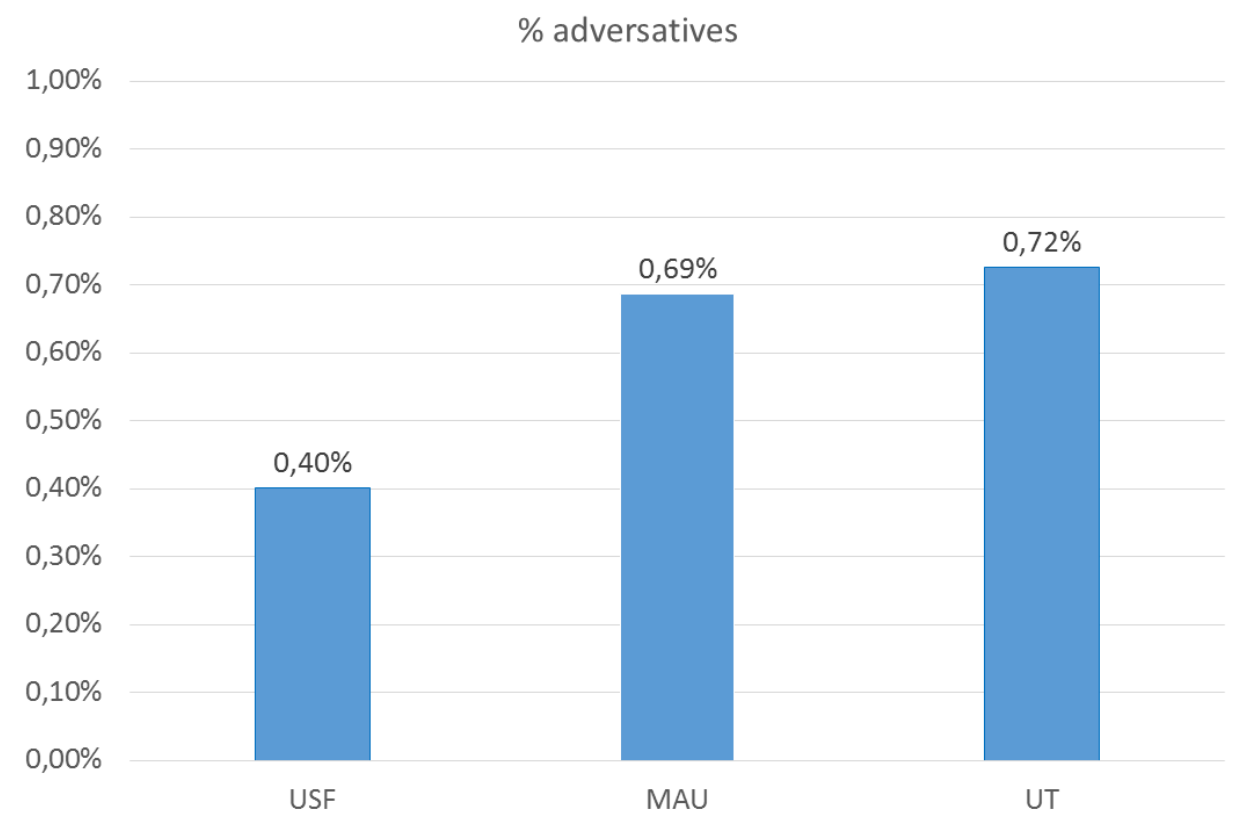

Figure 9. Distribution of adversative transitions

The USF students signal disalignment the least, which is also consistent with them being the least directive and the least present as reviewers (Table 2 and Figure 7). Based on the distribution of adversative transitions, the USF students may be perceived as unsure or, alternatively, protective of their own and their peers' faces, which seems to contradict the overuse of boosters in the USF data (Figure 4). In the present study, we do not control for the collocation patterns, but the underuse of adversative transitions in USF in comparison to MAU and UT suggests that the USF boosters may collocate more frequently with positively glossed expressions than MAU or UT boosters.

Aull and Lancaster (2014) find that across different populations - beginner students, experienced students, and professional academic writers - the least experienced writers use the most adversative transitions, but this decreases with experience. In our data, the beginner USF students use adversative transitions the least, while the beginner MAU students use almost as many adversative transitions as the experienced UT students. We may speculate that the prevalence of adversative transitions in ESL/EFL data is part of L2 training. By extension, when it comes to adversative transitions in this data, we can, perhaps, draw a parallel between the native speaker linguistic competence and the linguistic competence of experienced writers in Aull and Lancaster's study.

Table 6. Most frequent adversative transitions

USF

$\begin{array}{lll}1 & \text { however } & 16462 \\ 2 & \text { though } & 5492 \\ 3 & \text { although } & 3569 \\ 4 & \text { while } & 2727 \\ 5 & \text { still } & 2371 \\ 6 & \text { besides } & 1413 \\ 7 & \text { either } & 1013 \\ 8 & \text { yet } & 820 \\ 9 & \text { at least } & 762 \\ 10 & \text { even though } & 711\end{array}$

\section{MAU}

however though still yet although at least either while even though but

\section{UT}

845 however 98

409 still 93

244 yet 53

236 although 46

226 at least 41

137 though 36

104 while 32

103 either 15

68 besides 12

50 indeed 11


However, there is a clear difference between the range of individual transitions in the three data sets (Table 6). The experienced writers at UT frequently use a range of different transitions, while the beginner students at USF and MAU rely heavily on one transition: however. The frequency of however in institutional writing in The Spoken and Written Academic Language corpus (T2K-SWAL, Biber 2006) is 0,05\%. Compared to our data, the beginner USF students use however most frequently $(0,24 \%)$, the beginner MAU students almost as frequently $(0,22 \%)$, and the experienced UT students the least frequently $(0,15 \%)$. The frequency of however, but not the general frequency of adversative transitions across the three contexts, is consistent with Aull and Lancaster (2014). Further study may resolve this conflict in the data.

\section{Conclusions}

This study has quantitatively explored features of affective language coding criticism and praise in peer reviews: adjectives, expressions of suggestion, boosters and hedges, cognitive verbs, personal pronouns, and adversative transitions. Corpus analysis of large samples of peer review data has shown that peer reviewers across contexts exhibit a similar blend of foci: they describe, evaluate, direct, suggest, react, and interpret. They tend to do so in positively glossed language. These elements seem to be common in peer reviews despite the disparate contexts in which they are performed. However, each context also displays an idiosyncratic or even inconsistent mix of affective discourse indicators, i.e. none of the contexts displays a uniquely identifying combination of the linguistic expressions. The percentage differences of feature distributions between the contexts were small, yet interestingly suggestive. Explaining the distribution of these expressions involves reference to the peer reviewer's academic writing experience, whether the peer reviewer is a native speaker or a learner of English, or the institutional context. Although previous research, often contextually and empirically limited, has strongly suggested several common genre features of peer review, our "real-world" data offers a more complex and challenging take on peer review discourse and its contexts: we cannot yet formulate strong claims as to what explanation can be invoked for a particular expression or combination of expressions in the different contexts or across contexts.

The nature of "real-world" data in this study, of course, limits the generalizability of the conclusions, which could be amended by harmonizing data sets and applying statistical methods for analysis. In the present study, the data does not lend itself to such harmonization and statistical analyses: the data sets are simply too different in size. At the same time, with the further development and spread of digital tools for writing, the availability of such disparate, "real-world" data as ours is becoming more common. Exploratory research is needed to figure out what kinds of questions can be fruitfully put to such data and what kind of methods and methodologies can be pursued.

Despite the above limitations, the study provides some insights into the strategies students employ when peer reviewing. Since the three moves we have identified in our data are characteristic for staging criticism and praise across all three contexts under investigation, they can be capitalized upon when preparing students to peer review. For example, in our data, native speakers seem generally less confrontational, while non-native speakers express disalignment with the writer more often. However, this disalignment is mitigated in the nonnative data by the extensive use of hedges and cognitive verbs. Perhaps if such mitigation strategies are made explicit to native speakers in the context of peer review, they may experience peer review situations as less face-threatening: native-speaker students may then become as assertive expressing constructive criticism as they are expressing praise. Novice students in our data, both native and non-native speakers, have also demonstrated a limited repertoire of evaluative adjectives. Therefore, perhaps novice students in particular should be offered a set of adjectives to help them express criticism and praise in peer reviews precisely and effectively. Moreover, students can be instructed to focus on their experiences as readers and reviewers, instead of focusing on what the writer did or did not do, which may further reduce the potentially face-threatening aspects of the peer-review situation. 


\section{References}

Ağçam, R., and Özkan, M. (2015) 'A Corpus-based Study on Evaluation Adjectives in Academic English'. Procedia - Social and Behavioral Sciences 199, 3-11. DOI: 10.1016/j.sbspro.2015.07.480

Aijmer, K. (2013) Understanding Pragmatic Markers: A Variational Pragmatic Approach. Edinburgh: Edinburgh University Press

Anthony, L. (2017) 'AntConc (Version 10.7-10.10) [Macintoch OS X]'. Tokyo, Japan: Waseda University. [online] available from <http://www.laurenceanthony.net/> [2 July 2018]

Aull, L. (2015) First-year University Writing: A Corpus-Based Study with Implications for Pedagogy. Houndmills, Basingstoke, Hampshire: Palgrave Macmillan. DOI: $10.1057 / 9781137350466$

Aull, L. L., Bandarage, D., and Miller, M. R. (2017) 'Generality in Student and Expert Epistemic Stance: A Corpus Analysis of First-year, Upper-level, and Published Academic Writing'. Journal of English for Academic Purposes 26, 29-41. DOI: 10.1016/j.jeap.2017.01.005

Aull, L. L., and Lancaster, Z. (2014) 'Linguistic Markers of Stance in Early and Advanced Academic Writing: A Corpus-based Comparison'. Written Communication 31 (2), 1-33. DOI: $10.1177 / 0741088314527055$

Belcher, D., and Nelson, G. (2013) Critical and Corpus-based Approaches to Intercultural Rhetoric. Ann Arbor: The University of Michigan Press. DOI: 10.3998/mpub.5121451

Biber, D. (2006) University Language: A Corpus-based Study of Spoken and Written Registers. Amsterdam: John Benjamins. DOI: 10.1075/scl.23

Biber, D., Conrad, S., and Reppen, R. (2011) 'Corpus-based Approaches to Issues in Applied Linguistics'. In The Routledge Applied Linguistics Reader. ed. by Wei, L. London: Routledge, 185-201

Biber, D., Johansson, S., Leech, G., Conrad, S., and Finegan, E. (1999) Longman Grammar of Spoken and Written English. Harlow: Longman

Black, P., and Wiliam, D. (1998) 'Assessment and Classroom Learning'. Assessment in Education: Principles, Policy and Practice 5 (1), 7-74. DOI: 10.1080/0969595980050102

Brown, P., and Levinson, S. C. (1987) Politeness: Some Universals in Language Usage. Cambridge: Cambridge University Press

Bruffee, K. A. (1984) 'Collaborative Learning and the "Conversation of Mankind"'. College English 46 (7), 635-652. DOI: 10.2307/376924

Burstein, J., Elliot, N., and Molloy, H. (2016) 'Informing Automated Writing Evaluation Using the Lens of Genre: Two Studies'. CALICO Journal 33 (1), 117-141. DOI: 10.1558/cj.v33i1.26374

Chen, T. (2016) 'Technology-supported Peer Feedback in ESL/EFL Writing Classes: A Research Synthesis'. Computer Assisted Language Learning 29 (2), 365-397. DOI: 10.1080/09588221.2014.960942

Cheng, M. C. (2007) 'Improving Interaction and Feedback with Computer Mediated Communication in Asian EFL Composition Classes: A Case Study'. Taiwan Journal of TESOL 4 (1), 65-97 
Cho, K., and MacArthur, C. (2010) 'Student Revision with Peer and Expert Reviewing'. Learning and Instruction 20 (4), 328-338. DOI: 10.1016/j.learninstruc.2009.08.006

Cho, K., and Schunn, C. D. (2007) 'Scaffolded Writing and Rewriting in the Discipline: A Webbased Reciprocal Peer Review System'. Computers and Education 48, 409-426. DOI: 10.1016/j.compedu.2005.02.004

Choi, J. (2014) 'Online Peer Discourse in a Writing Classroom'. International Journal of Teaching and Learning in Higher Education 26 (2), 217-231

Chong, M. R., Goff, L., and Dej, K. (2012) 'Undergraduate Essay Writing: Online and Face-toface Peer Reviews'. Collected Essays on Learning and Teaching 5, 69-74. DOI: 10.22329/celt.v5i0.3423

Davies, P. (2006) 'Peer Assessment: Judging the Quality of Students' Work by Comments Rather Than Marks'. Innovations in Education and Teaching International 43 (1), 69-82. DOI: $10.1080 / 14703290500467566$

DeStigter, T. (2015) 'On the Ascendance of Argument: A Critique of the Assumptions of Academe's Dominant Form'. Research in the Teaching of English 50 (1), 11-34

Dixon, Z., and Moxley, J. (2013) 'Everything is Illuminated: What Big Data Can Tell Us about Teacher Commentary'. Assessing Writing 18 (4), 241-256. DOI: 10.1016/j.asw.2013.08.002

Dysthe, O., and Lillejord, S. (2012) 'From Humboldt to Bologna: Using Peer Feedback to Foster Productive Writing Practices among Online Master Students'. International Journal of Web Based Communities 8 (4), 471-485. DOI: 10.1504/IJWBC.2012.049561

Ferris, D. R. (1997) The Influence of Teacher Commentary on Student Revision'. TESOL Quarterly 31 (2), 315-339. DOI: 10.2307/3588049

Fitze, M. (2006) 'Discourse and Participation in ESL Face-to-face and Written Electronic Conferences. Language Learning and Technology 10 (1), 67-86

FrameNet (n.d.). 'About FrameNet'. University of California, Berkeley [online]. available from $<$ https://framenet.icsi.berkeley.edu/fndrupal/about> [2 July 2018]

Galbraith, D., and Rijlaarsdam, G. (1999). 'Effective Strategies for the Teaching and Learning of Writing'. Learning and Instruction 9 (2), 93-108. DOI: 10.1016/S0959-4752(98)00039-5

Garrison, D. R., Anderson, T., and Archer, W. (1999) 'Critical Inquiry in a Text-based Environment: Computer Conferencing in Higher Education'. The Internet and Higher Education 2 (2-3), 87-105. DOI: 10.1016/S1096-7516(00)00016-6

Geithner, C. A., and Pollastro, A. N. (2016) 'DOIng Peer Review and Receiving Feedback: Impact on Scientific Literacy and Writing Skills. Advances in Physiology Education 40 (1), 38-46. DOI: 10.1152/advan.00071.2015

Halliday, M. A. K., and Hasan, R. (1976) Cohesion in English. London: Longman

Hattie, J., and Timperley, H. (2007) 'The Power of Feedback'. Review of Educational Research 77 (1), 81-112. DOI: 10.3102/003465430298487

He, A. W. (1993) 'Language Use in Peer Review Texts'. Language in Society 22 (3), 403-420. DOI: $10.1017 /$ S0047404500017292 
Heath, S. B. (1993) 'Rethinking the Sense of the Past: The Essay as Legacy of the Epigram'. In Theory and Practice in the Teaching of Writing: Rethinking the Discipline. ed by Odell, L. Carbondale, IL: Southern Illinois University Press, 105-131

Hinkel, E. (2005) 'Hedging, Inflating, and Persuading in L2 Academic Writing'. Applied Language Learning 15 (1 and 2), 29-53

Huddlestone, R., and Pullum, G. K. (2002) The Cambridge Grammar of the English Language. Cambridge: Cambridge Univ. Press

Hyland, F., and Hyland, K. (2001) 'Sugaring the Pill: Praise and Criticism in Written Feedback'. Journal of Second Language Writing 10 (3), 185-212. DOI: 10.1016/S10603743(01)00038-8

Hyland, K. (2005) 'Stance and Engagement: A Model of Interaction in Academic Discourse'. Discourse Studies 7 (2), 173-192. DOI: 10.1177/1461445605050365

Hyland, K., and Hyland, F. (2006) 'Feedback on Second Language Students' Writing'. Language Teaching 39 (2), 83-101. DOI: 10.1017/S0261444806003399

Hyland, K., and Milton, J. (1997) 'Qualification and Certainty in L1 and L2 Students' Writing'. Journal of Second Language Writing 6 (2), 183-205. DOI: 10.1016/S10603743(97)90033-3

Kipper, K., Korhonen, A., Ryant, N., and Palmer, M. (2008) 'A Large-scale Classification of English Verbs'. Language Resources and Evaluation 42 (1), 21-40. DOI: 10.1007/s10579-007-9048-2

Kroll, B. (2001) 'Considerations for Teaching an ESL/EFL Writing Course'. In, Teaching English as a second or foreign language. $3^{\text {rd }}$ ed. ed by Celce-Murcia, M. Boston: Heinle and Heinle, 219-232

Landry, A., Jabobs, S., and Newton, G. (2015) 'Effective Use of Peer Assessment in a Graduate Level Writing Assignment: A Case Study'. International Journal of Higher Education 4 (1), 38-51. DOI: 10.5430/ijhe.v4n1p38

Lansiquot, R., and Rosalia, C. (2015) 'Online Peer Review: Encouraging Student Response and Development'. Journal of Interactive Learning Research 26 (1), 105-123

Leijen, D. A., and Leontjeva, A. (2012) 'Linguistic and Review Features of Peer Feedback and their Effect on the Implementation of Changes in Academic Writing: A Corpus Based Investigation'. Journal of Writing Research 4 (2) 177-202. DOI: 10.17239/jowr2012.04.02.4

Leijen, D. A. (2017) 'A Novel Approach to Examine the Impact of Web-based Peer Review on the Revisions of L2 Writers'. Computers and Composition 43, 35-54. DOI: 10.1016/j.compcom.2016.11.005

Li, F., Huang, M., and Zhu, X. (2010) 'Sentiment Analysis with Global Topics and Local Dependency'. In Twenty-Fourth AAAI Conference on Artificial Intelligence. [online] available from <http://www.aaai.org/ocs/index.php/AAAl/AAAl10/paper/view/1913> [2 July 2018]

Liang, M. Y. (2008) 'SCMC Interaction and Writing Revision: Facilitative or Futile?'. In Proceedings of the World Conference on ELearning in Corporate, Government, Healthcare, and Higher Education 2008. Cheasepeake, VA: AACE, 2886-2892. [online] available from <https://www.learntechlib.org/j/ELEARN/v/2008/n/1/> [2 July 2018] 
Liou, H.-C., and Peng, Z.-Y. (2009) 'Training Effects on Computer-mediated Peer Review. System 37 (3), 514-525. DOI: 10.1016/j.system.2009.01.005

Liu, J., and Sadler, R. W. (2003) 'The Effect and Affect of Peer Review in Electronic versus Traditional Modes on L2 Writing'. Journal of English for Academic Purposes 2 (3), 193227. DOI: 10.1016/S1475-1585(03)00025-0

Lockhart, C., and Ng, P. (1995) 'Analyzing Talk in ESL Peer Response Groups: Stances, Functions, and Content'. Language Learning 45 (4), 605. DOI: 10.1111/j.14671770.1995.tb00456.x

Lundstrom, K., and Baker, W. (2009) 'To Give is Better Than to Receive: The Benefits of Peer Review to the Reviewer's Own Writing'. Journal of Second Language Writing 18 (1), 3043. DOI: $10.1016 / j . j s l w .2008 .06 .002$

MacArthur, C. A. (2016) 'Instruction in Evaluation and Revision'. In Handbook of Writing Research. 2nd ed. ed. by MacArthur, C. A., Graham, S. and Fitzgerald, J. New York, N.Y.: Guilford, 272-287

Manovich, L. (2012) 'Trending: The Promises and the Challenges of Big Social Data'. In Debates in the Digital Humanities. ed by Gold, M. K. [Electronic resource] University of Minnesota Press, 460-475. DOI: 10.5749/minnesota/9780816677948.003.0047

Mirador, J. (2014) 'Moves, Intentions and the Language of Feedback Commentaries in Education'. Indonesian Journal of Applied Linguistics 4 (1), 39-53. DOI: 10.17509/ijal.v4i1.599

Moxley, J. (2013) 'Big Data, Learning Analytics, and Social Assessment Methods'. The Journal of Writing Assessment 6 (1)

Moxley, J. M., and Eubanks, D. (2016) 'On Keeping Score: Instructors' vs. Students' Rubric Ratings of 46,689 Essays'. WPA: Writing Program Administration - Journal of the Council of Writing Program Administrators 39 (2), 53-80

Nelson, M. M. (2007) The Nature of Feedback: How Different Types of Peer Feedback Affect Writing Performance. University of Pittsburg. [online] available from <http://dscholarship.pitt.edu/10148/> [2 July 2018]

Nelson, M. M., and Schunn, C. D. (2009) 'The Nature of Feedback: How Different Types of Peer Feedback Affect Writing Performance'. Instructional Science 37 (4), 375-401. DOI: 10.1007/s11251-008-9053-X

Nguyen, T. T. M. (2008) 'Modifying L2 Criticisms: How Learners Do It?'. Journal of Pragmatics 40 (4), 768-791. DOI: 10.1016/j.pragma.2007.05.008

Nicol, D., Thomson, A., and Breslin, C. (2014) 'Rethinking Feedback Practices in Higher Education: A Peer Review Perspective'. Assessment and Evaluation in Higher Education 39 (1), 102-122. DOI: 10.1080/02602938.2013.795518

Olsson Jers, C. and Wärnsby, A. (2017) 'Assessment of Situated Orality: The Role of Reflection and Revision in Appropriation and Transformation of New Knowledge'. Assessment and Evaluation in Higher Education 43 (4), 586-597. DOI: 10.1080/02602938.2017.1383356

Patchan, M. M., Schunn, C. D., and Correnti, R. J. (2016) 'The Nature of Feedback: How Peer Feedback Features Affect Students Implementation Rate and Quality of Revisions'. Journal of Educational Psychology 108 (8), 1098-1120. DOI: 10.1037/edu0000103

Quirk, R., Greenbaum, S., Leech, G., and Svartvik, J. (1985) A Comprehensive Grammar of the English Language. Harlow: Longman 
Rocklage, M. D., and Fazio, R. H. (2015) 'The Evaluative Lexicon: Adjective Use as a Means of Assessing and Distinguishing Attitude Valence, Extremity, and Emotionality'. Journal of Experimental Social Psychology 56, 214-227. DOI: 10.1016/j.jesp.2014.10.005

Rourke, L., Anderson, T., Garrison, D. R., and Archer, W. (1999) 'Assessing Social Presence in Asynchronous Text-based Computer Conferencing'. Journal of Distance Education 14 (2), 50-71

Shute, V. J. (2008) 'Focus on Formative Feedback'. Review of Educational Research 78 (1), 153-189. DOI: 10.3102/0034654307313795

Sullivan, N., and Pratt, E. (1996) 'A Comparative Study of two ESL Writing Environments: A Computer-assisted Classroom and a Traditional Oral Classroom'. System 24 (4), 491501. DOI: 10.1016/S0346-251X(96)00044-9

Sundqvist, P., and Sylvén, L. K. (2014) 'Language-related Computer Use: Focus on Young L2 English Learners in Sweden'. ReCALL 26 (1), 3-20. DOI: 10.1017/S0958344013000232

Ushioda, E. (2013) 'Motivation and ELT: Global Issues and Local Concerns'. In International Perspectives on Motivation: Language Learning and Professional Challenges. ed. by Ushioda, E. Basingstoke: Palgrave Macmillan, 1-17

VerbNet. (n.d.) 'A Class-based Verb Lexicon'. Martha Palmer, University of Colorado Boulder [online]. available from <https://verbs.colorado.edu/ mpalmer/projects/verbnet.html> [2 July 2018]

Vygotsky, L. S. (1978) Mind in Society: The Development of Higher Psychological Processes. Cambridge, Massachusetts: Harvard University Press

Ware, P. D. (2004) 'Confidence and Competition Online: ESL Student Perspectives on Webbased Discussions in the Classroom'. Computers and Composition 21 (4), 451-468. DOI: 10.1016/S8755-4615(04)00041-6

Wärnsby, A. (2006) (De)coding modality: The case of Must, May, Måste and Kan. In Lund Studies in English, 113. ed. by Thormählen, M. and B. Warren. Lund: Department of English, Centre for Languages and Literature, Lund University

Warschauer, M. (2002) 'Networking into Academic Discourse'. Journal of English for Academic Purposes 1 (1), 45-58. DOI: 10.1016/S1475-1585(02)00005-X

Yallop, R. M. A. (2016) 'Measuring Affective Language in Known Peer Feedback on L2 Academic Writing Courses'. Eesti Rakenduslingvistika Ühingu aastaraamat 12, 287-308. DOI: 10.5128/ERYa12.17

Yelland, C. (2011) 'A Genre and Move Analysis of Written Feedback in Higher Education'. Language and Literature 20 (3), 218-235. DOI: 10.1177/0963947011413563 


\section{Appendix}

\begin{tabular}{|c|c|c|c|c|}
\hline Adjectives & 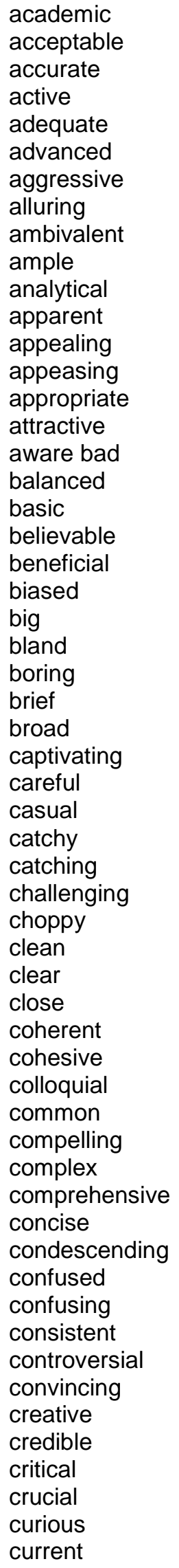 & $\begin{array}{l}\text { descriptive } \\
\text { detailed developed } \\
\text { different } \\
\text { difficult } \\
\text { disconnected } \\
\text { discouraged } \\
\text { disputable } \\
\text { distinct } \\
\text { disturbing } \\
\text { dramatic easy } \\
\text { effective } \\
\text { efficient } \\
\text { emotional } \\
\text { engaging } \\
\text { enjoyable } \\
\text { ethical } \\
\text { evaluative } \\
\text { evident } \\
\text { exciting } \\
\text { explanatory } \\
\text { explicit } \\
\text { factual } \\
\text { familiar } \\
\text { fitting } \\
\text { flexible } \\
\text { fluent } \\
\text { focused } \\
\text { formal } \\
\text { fragile } \\
\text { fragmented } \\
\text { general } \\
\text { gifted } \\
\text { laske } \\
\text { legood } \\
\text { lengthy } \\
\text { great } \\
\text { intriguing } \\
\text { hard } \\
\text { harsh } \\
\text { helpful } \\
\text { high } \\
\text { hot } \\
\text { illustrative } \\
\text { important } \\
\text { impressive } \\
\text { inaccurate } \\
\text { inclusive } \\
\text { ineffective } \\
\text { informal } \\
\text { informative } \\
\text { informative } \\
\text { lable } \\
\text { inting } \\
\text { ingeate }\end{array}$ & 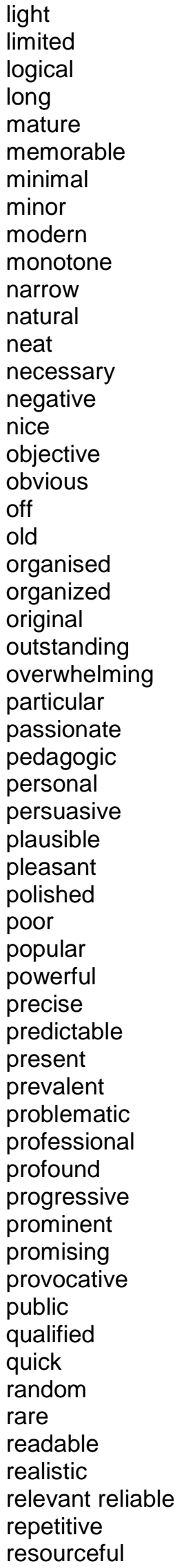 & 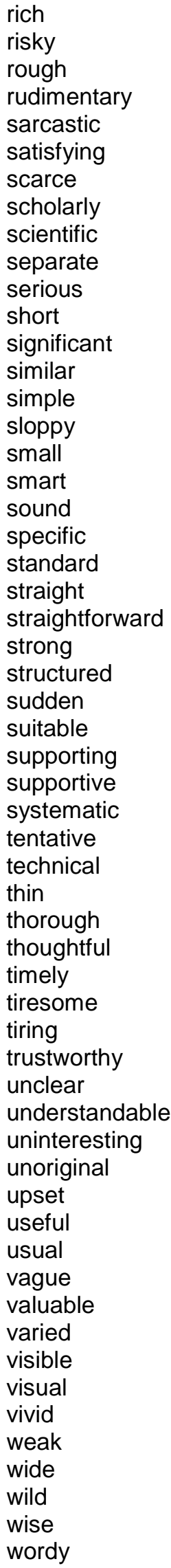 \\
\hline
\end{tabular}


decent

Expressions
of
suggestion

\section{Boosters and hedges}

better you should

you could

always
certain
certainly
clear
clearly

conclusively

decidedly

definite

definitely

incontestable

incontestably

incontrovertible

incontrovertibly

indisputable

indisputably

known

never

no doubt

doubtless

undoubtedly

sure

surely

very

extremely

more

really

undeniably

undeniable

quite

fully

must

beyond doubt

indeed certain

had indeed

one indeed

this indeed

indeed makes

indeed become

indeed make

indeed there

was indeed

were indeed

is indeed

there indeed

indeed do

indeed very

are indeed

it indeed

humans indeed

have indeed

has indeed

indeed those you may

you might

I recommend

indeed rare

indeed fortunate

fortunate indeed

ironic indeed

indeed ironic

indeed impressive

impressive indeed

indeed bleak

bleak indeed

indeed startling

startling indeed

indeed daunting

daunting indeed

indeed unfortunate

unfortunate indeed

shocking indeed

indeed shocking

indeed important

indeed capable

can indeed

will indeed

indeed does

indeed did

correct indeed

indeed correct

did indeed

indeed

encourage

true indeed

indeed enhance

does indeed

should indeed

society indeed

that indeed

would indeed

not true

without doubt

of course

not replicable

not realistically

definitely not

absolutely no

no doubting

can literally

should not

should only

should never

should know

has to

have to

needs to

need to respectful

I suggest

better not

you ought to

appear

appears

appeared

appearing

tend

tended

tends

might

may

estimation

suggestion

indication

appearance

almost

probably

relatively

roughly

somewhat

typical

typically

uncertain

uncertainly

unclear

unclearly

unlikely

usually

oftentimes

perhaps

plausible

plausibly

possible

possibly

possibility

possibilities

presumably

presumable

probable

largely

likely

mainly

maybe

mostly

often

basically

broadly

doubtful

approximately

fairly

frequently

generally

might not

may not wrong

you may want to

you might want to

I would like to

not usually

practically no

can potentially

not established

doubt that

in general

not quite

rather common

rather different

rather small

rather large

rather limited

rather low

rather high

rather difficult

rather obvious

rather narrow

rather simple

rather simply

rather simplistic

rather complex

rather like

rather modest

rather vague

rather unique

rather unusual

rather weak

rather short

rather surprising

rather similar

not automatically

not technically

cannot fully

never fully

more fully

ever fully

don't fully

can't fully

doesn't fully

didn't fully

may be true

may prove true

could be true

could prove true

can be true

can prove true

is not known

are not known

not yet known

is not proved

are not proved

not unheard of 


\begin{tabular}{|c|c|c|c|c|}
\hline & $\begin{array}{l}\text { indeed our } \\
\text { and indeed } \\
\text { she indeed } \\
\text { he indeed } \\
\text { people indeed } \\
\text { which indeed } \\
\text { many indeed } \\
\text { they indeed } \\
\text { we indeed } \\
\text { as indeed } \\
\text { indeed the } \\
\text { but indeed } \\
\text { yet indeed } \\
\text { not indeed } \\
\text { indeed help } \\
\text { indeed work } \\
\text { indeed true } \\
\text { indeed necessary } \\
\text { indeed more } \\
\text { important indeed } \\
\text { rare indeed }\end{array}$ & $\begin{array}{l}\text { had better } \\
\text { to fully } \\
\text { has got to } \\
\text { have got to } \\
\text { no way to } \\
\text { no way of } \\
\text { there are no } \\
\text { exceptions } \\
\text { there is no } \\
\text { question } \\
\text { indicate } \\
\text { indicates } \\
\text { indicated } \\
\text { suggest } \\
\text { suggests } \\
\text { suggested } \\
\text { seems } \\
\text { seem } \\
\text { seemed }\end{array}$ & $\begin{array}{l}\text { not always } \\
\text { not thoroughly } \\
\text { not certain } \\
\text { certain amount } \\
\text { certain extent } \\
\text { certain level } \\
\text { not clear } \\
\text { not indisputable } \\
\text { not known } \\
\text { some doubt } \\
\text { not sure } \\
\text { not very } \\
\text { not really } \\
\text { not undeniable } \\
\text { not entirely } \\
\text { not completely } \\
\text { not definitely } \\
\text { not everybody } \\
\text { not overly } \\
\text { not unusual }\end{array}$ & $\begin{array}{l}\text { most of the } \\
\text { in most cases } \\
\text { in most instances } \\
\text { on the whole } \\
\text { not yet proved } \\
\text { is not proven } \\
\text { are not proven } \\
\text { not yet proven } \\
\text { is not established } \\
\text { are not established } \\
\text { could well be true } \\
\text { may well be true } \\
\text { might well be true } \\
\text { is also not known } \\
\text { is also not proved } \\
\text { are also not proved } \\
\text { are also not proved } \\
\text { is also not established } \\
\text { are also not established } \\
\text { for the most part }\end{array}$ \\
\hline $\begin{array}{l}\text { Cognitive } \\
\text { verbs }\end{array}$ & $\begin{array}{l}\text { know } \\
\text { perceive } \\
\text { prefer } \\
\text { understand } \\
\text { recognise } \\
\text { recognize }\end{array}$ & $\begin{array}{l}\text { wonder } \\
\text { like appreciate } \\
\text { puzzles } \\
\text { puzzled } \\
\text { think } \\
\text { believe }\end{array}$ & $\begin{array}{l}\text { question } \\
\text { grasp comprehend } \\
\text { suppose } \\
\text { imagine } \\
\text { maintain }\end{array}$ & $\begin{array}{l}\text { guess } \\
\text { suspect } \\
\text { feel } \\
\text { consider } \\
\text { seem } \\
\text { interpret }\end{array}$ \\
\hline $\begin{array}{l}\text { Personal } \\
\text { pronouns }\end{array}$ & $\begin{array}{l}\text { I } \\
\text { my } \\
\text { mine }\end{array}$ & $\begin{array}{l}\text { me } \\
\text { we } \\
\text { our }\end{array}$ & $\begin{array}{l}\text { ours } \\
\text { us } \\
\text { you }\end{array}$ & $\begin{array}{l}\text { your } \\
\text { yours }\end{array}$ \\
\hline $\begin{array}{l}\text { Adversative } \\
\text { transitions }\end{array}$ & $\begin{array}{l}\text { admittedly } \\
\text { albeit } \\
\text { although } \\
\text { besides } \\
\text { but }\end{array}$ & $\begin{array}{l}\text { contrary } \\
\text { conversely } \\
\text { either } \\
\text { granted } \\
\text { however }\end{array}$ & $\begin{array}{l}\text { indeed } \\
\text { nevertheless } \\
\text { nonetheless } \\
\text { notwithstanding } \\
\text { regardless }\end{array}$ & $\begin{array}{l}\text { still } \\
\text { though } \\
\text { whereas } \\
\text { while } \\
\text { yet }\end{array}$ \\
\hline
\end{tabular}

